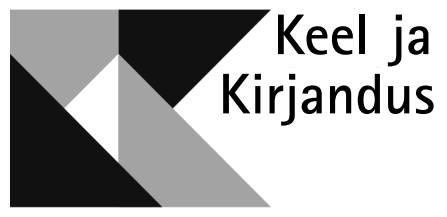

$6 / 2018$

LXI AASTAKÄIK

EESTI TEADUSTE AKADEEMIA JA EESTI KIRJANIKE LIIDU AJAKIRI

\title{
VARJATUD MUUTUSED EESTI KEELE PROSOODILISES STRUKTUURIS
}

\author{
KÜLLI PRILLOP
}

$\mathrm{E}$ esti foneetikud on juba mitukümmend aastat otsinud vastust küsimusele, missugust rolli mängib vältevastanduses põhitooni muutumine. Kas väldete tajumisel on kõige olulisem tunnus kestuste erinevus või hoopis sõna põhitoonikontuur? Mitmed uurimused on näidanud, et põhitoon tõepoolest on II ja III välte eristamisel tähtis (vt põhjalikku ülevaadet Lippus 2016: 140-148). Ilse Lehiste (2003) on välja käinud arvamuse, et eesti keel on muutumas kvantiteedikeelest tooniaktsendikeeleks. Tooniaktsendid on iseloomulikud mitmele Läänemere regiooni keelele, nt kui hääldada Stockholmi rootsi keeles sõna anden esisilp tõusva ja järgsilp langeva tooniga, tähendab see 'part', kui aga toon esisilbi hääldamisel langeb, teise silbi alguses tõuseb ja lõpuks taas langeb, on tähenduseks 'vaim'. Nn päris toonikeeltest eristab tooniaktsendikeeli see, et toonide esinemine oleneb sõna rõhust, silpide arvust või morfoloogilisest struktuurist (vt Karlsson 2002: 82)1.

Kui eesti keel on tõesti muutumas tooniaktsendikeeleks, siis kuidas seda fonoloogiliselt kirjeldada? Mis täpsemalt juhtub eesti keele struktuuriga ning millised varasemad keelemuutused on uute eelduseks? Siinses artiklis kirjeldan pikkuskontrastide teisenemist põhitoonikontrastideks ning selle eelduseks olevaid muutusi, lähtudes tänapäevasest moorateooriast (Hyman 1985; Hock 1986; McCarthy, Prince 1986; Hayes 1989 jpt). Moora (tähistatakse kreeka tähega $\mu$ ) on prosoodilise struktuuri üksus, mis kuulub silpi $(\sigma)$. Silbid omakorda on jalgade (F) moodustajad ning jalgadest pannakse kokku prosoo-

${ }^{1}$ Mõistet tooniaktsent kasutatakse ka lausungi intonatsioonikontuuri kirjeldamisel. 
dilised sõnad ( $\omega)$. Moora põhiülesanne on eristada rõhusüsteemide jaoks olulisi silbistruktuure: kerges silbis on üks moora, raskes kaks. Rasked silbid võivad sõnarõhu enesele tõmmata. Lisaks on mooral kui prosoodilisel üksusel võime muuta hääliku kestust: lühike vokaal on seotud ühe mooraga, pikk kahega. Mooraga on seotud ka geminaatkonsonandid.

Artikkel on jätkuks uurimusele „Mida teeb moora eesti keeles?” (Prillop 2018), kus andsin ülevaate moora rollist prosoodilises struktuuris ning kirjeldasin eesti keele välteid stabiilse süsteemina. Nüüd võtan vaatluse alla vältesüsteemi perifeersed, ebastabiilsed osad, mis lõpuks võivadki viia eesti keele muutumiseni tooniaktsendikeeleks.

Lähtun tabelis 1 esitatud vältekäsitlusest (Prince 1980; Prillop 2013, 2015), mille järgi III välde eristub I ja II vältest selle poolest, et III vältes täidab rõhuline silp üksi kogu jala, aga I ning II vältes on jalas kaks silpi. Kahesilbilise III-vältelise sõna teine silp jääb jalaväliseks, mis tingib selle silbi vokaali redutseerumise. I ja II välde eristuvad rõhulise silbi struktuuri poolest. Tabeli näitesõnadesse lisatud punktid märgivad silbipiire ning jalad on eraldatud sulgudega. Pikendusmärk : tähistab lisamoorat (st kahemooralist vokaali või ühemooralist konsonanti) ning poolpikkuse märk - jala viimase moora pikenemist (märgitud ainult III vältes, kus see on tähenduste eristamiseks oluline). Geminaatkonsonant on kirjutatud kahe tähega juhul, kui on vaja näidata geminaadi sisse jäävat silbipiiri. Oluline on aga meeles pidada, et häälduses on siiski tegemist ühe pika konsonandiga, järjekindlat topeltartikulatsiooni ei toimu (vt Lippus 2016: 136-137). Kui silbis on pikk vokaal, millele järgneb pikk konsonant, siis pole silbis kokku kolme moorat, vaid vokaal ja konsonant on ühendatud sama mooraga (joonis 1).

\section{Eesti keele vältesüsteem}

Tabel 1.

\begin{tabular}{|c|c|c|c|}
\hline Välde & I & II & III \\
\hline Esisilp & kerge & \multicolumn{2}{|c|}{ raske } \\
\hline Jalg & \multicolumn{2}{|c|}{$(\sigma \sigma)$} & $(\sigma) \sigma$ \\
\hline Näited & (u.te) - ude & $\begin{array}{l}\text { (u:te)-uude } \\
\text { (ut:.te)-ute } \\
\text { (u:t:.te)-uute }\end{array}$ & $\begin{array}{l}\left(\mathrm{u}:{ }^{\prime}\right) \cdot \mathrm{te}-\text { uude } \\
\left(\mathrm{ut}:{ }^{\prime}\right) \cdot \mathrm{te}-\text { utte } \\
(\mathrm{u}: \mathrm{t}:) \cdot \mathrm{te}-\text { uute }\end{array}$ \\
\hline
\end{tabular}

a. II välde

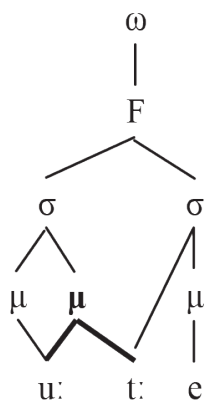

b. III välde

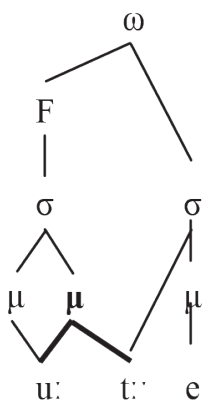

J o on is 1 . Moora jagamine sõna uute esisilbis. 


\section{Silbi kooda nõrgenemine}

Tänapäevase moorateooria järgi on võimalikud nii kerged kui ka rasked kinnised silbid. Esimesel juhul ei ole silbi kooda (s.o silpi sulgev konsonant) mooraga seotud, teisel juhul aga on; vt joonist 2. Koodale lisatakse moora siis, kui seda nõuab asendikaalu (ingl weight by position) reegel (Hayes 1989: 258, 1995: 52), st enamasti ei ole kooda mooralisus leksikaalne, see ei erista tähendusi.

Keeltes, kus asendikaalu reegel on aktiivne, on kinnised silbid rasked ning mõjutavad rõhu asukohta sõnas. Niisugune on näiteks ladina keel. Isegi keeltes, kus pearõhk (') on kinnistunud esisilbile ja taktid on kahesilbilised silbi raskusest sõltumata, võib kaasrõhk (,) kanduda lühikeselt silbilt järgnevale pikale: näiteks soome keeles /('pu.he).(li.me).(na.ni)/ 'minu telefonina', aga /('pu.he).li.(mis.ta).ni/ 'minu telefonidest' (Alber 1997; Elenbaas, Kager 1999). Sama tavalised on ka keeled, kus kooda pole kunagi mooraga seotud ning rõhusüsteemi jaoks on CVC-silbid samaväärsed CV-silpidega. Näiteks sölkupi keeles (Kager 2007: 197) on rõhk sõna viimasel raskel silbil (nt/qu.mo:.qlı. 'lr:/'sinu kaks sõpra'), raske silbi puudumisel aga esisilbil. CVC on kerge, sest vastasel juhul peaks nt sõnas /'qolj.cim.pa.ti/ 'leitud' olema rõhuline teine, mitte esimene silp.

a. Kerge silp b. Raske silp

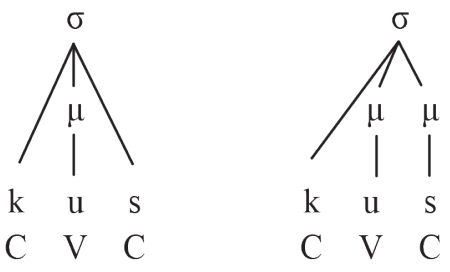

J o o n is 2. Kerge ja raske CVC-struktuuriga silp.

Võimalik on seegi, et ainult teatud tingimustele vastavad koodakonsonandid on mooraga seotud. Leedu keeles on sonoorse koodaga CVC-silbid rasked, obstruendiga lõppevad silbid aga kerged (Morén 2003: 291). Kašmiiri keeles (indoeuroopa keelkonna India rühm) on CVC raske ainult sel juhul, kui sõnas pole CVV-silpi, mis tõmbaks rõhu enesele, st CVC-silbi muudab raskeks tema sattumine rõhulisse positsiooni, mitte asendikaalu reegel: /'ba:.la:.dər/ 'balkon' illustreerib, et rõhk on esimesel raskel silbil; /vah. 'ra:.vun/ 'laieneda' lisaks seda, et CVC pole raske, ning /yu.nu. 'var.si.ti/ 'ülikool', et rõhuline CVC on raske, sest muidu oleks rõhk esimesel silbil (Davis 2014: 109-112, 127-128).

Eesti keeles on igal juhul mooraga seotud III-vältelise sõna esisilbi kooda, sest ainult nii tekkib kahemooraline silp, mis saab moodustada omaette jala. Eksisteerib universaalne nõue, mille järgi peab jalg olema minimaalselt kahemooraline, aga maksimaalselt kahesilbiline (Hayes 1995: 71; Kager 1999: 184). II-vältelistes sõnades ei ole aga esisilbist omaette jalga vaja moodustada, nii et see silp võiks vabalt olla ka ühemooraline, nagu ongi sõnades pudru, ludri jt (vt joonist 3). Muidugi ei saa ühemooraline olla pika vokaaliga esisilp ega ka fortisega lõppev esisilp, sest pikk vokaal on defineeritud kui kahemooraline vokaal ning fortis on mooraga seotud konsonant, mis koos lühikese vokaaliga moodustab raske silbi (nt sõnas nitro joonisel $3 b$ ). 

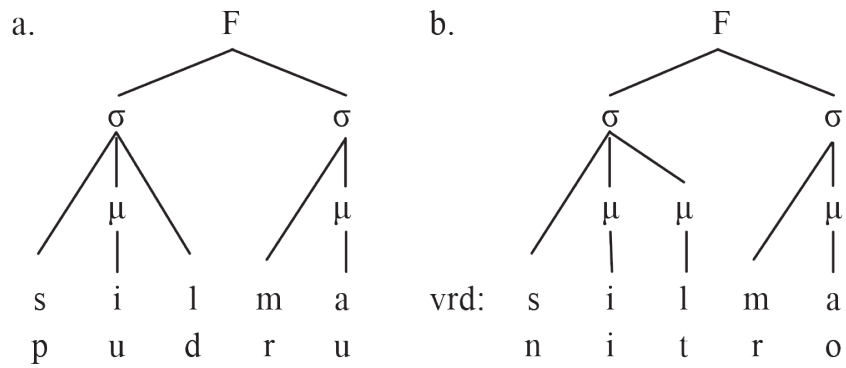

J o o n is 3. II-vältelise silma võimalikud struktuurivariandid.

Õigupoolest võibki niisuguste sõnade olemasolu nagu pudru ja nitro, samuti saag, saak jmt, olla tõendiks, et eesti keeles asendikaalu reegel ei toimi, sest see hävitaks tähenduste eristamiseks vajaliku fonoloogilise kontrasti: erinevuse leeniste ja fortiste vahel. Leenisklusiilid (ortograafias sõnasiseselt enamasti $g, b$ ja $d$ ) ei ole leksikaalselt mooraga seotud ega tohi seda seost luua ka pindstruktuuris, sest just mooraga seondumatus eristab neid nn fortisklusiilidest (ortograafias enamasti $k, p$ ja $t$ ). Viimased on leksikaalselt mooraga seotud. Leksikonis on mooraga seotud ka geminaatkonsonandid, et eristada neid üksikkonsonantidest (nt vrd kanna ja kana), kuid sonoorsete konsonantide puhul ei ole vahet, kas lubada koodasse jääv üksik konsonant mooraga siduda või mitte, sest sonoorse konsonandi mooralisus selles positsioonis tähendusi ei erista. II ja III välte pikkuserinevus tuleneb jala viimase moora pikenemisest, mitte selle moora olemasolust või puudumisest (vt tabelit 1 eespool).

Kui eesti keeles ei ole koodad üldjuhul mooraga seotud (joonis 2a), siis III vältes on kooda mooralisuse põhjuseks sõna jalastruktuur (umbes nagu kašmiiri keeles), aga mitte asendikaalu reegel. Selline tõlgendus vähendab süva- ja pindstruktuuri erinevusi. Kui asendikaalu reegel eesti keeles siiski on aktiivne (joonis $2 b$ ), peab see olema blokeeritud obstruentide puhul - süva- ja pindstruktuuri erinevused oleksid üsna keerukad.

On huvitav, et eesti keele rõhusüsteem ei aita otsustada CVC-silpide raskuse üle. Mati Hint (1973: 154-165) kirjeldab küll rõhu nihkumist kolmandalt silbilt neljandale, kui kolmas silp on lühike, nt /('kar.va).(, se.ma).( le.ki)/ /('kar.va).se.( ma.le).gi/ ning /('va.ra).( se.mat:).te/ /('va.ra).se.(, mat:.te)/, kuid välistab sellise rõhunihke kinniste silpide puhul, nt ainult /('ka.va).(lat:.te).le/ ja /('ka.va).(lus.te).le/. Hindi esitatud reeglid ei ole siiski piisavad, otsustamaks CVC-silpide kaalu üle. Näiteid leidub vaid selliste CVC-struktuuriga järgsilpide kohta (v.a sõnalõpulised silbid), mis on kahemooralised juba leksikonis ega anna seetõttu mingit infot asendikaalu reegli aktiivsuse kohta. Lisaks on näiteid $s$-lõpuliste silpide kohta, mis käituvad nagu rasked silbid. Paraku esinevad need vaid $u s$-liiteliste sõnade mitmusevormides, kus $s$-ile liitub tunnus -t.e. Tegemist võib olla t:e-tunnuse algusklusiili moora siirdumisega eelneva silbi koodasse või hoopiski morfoloogiliselt määratud rõhuga (nii nagu mine- või lik-liide on enamasti kaasrõhulised). Ka sõnast iluduselegi esitab Hint (1973: 163) ainult niisuguse variandi, kus kaasrõhk 
langeb us-liitele, kuigi muudes kuuesilbilistes lühikeste silpidega sõnades on võimalik ka rõhu nihkumine kolmandale silbile: vrd /(,i.lu).(, tu.se).(, le.ki)/ ja /('o.sa).(, va.ma).( le.ki)/ /('o.sa).va.(, ma.le).ki/.

Eesti keele sõnalõpulisi konsonante on mitmed autorid pidanud meetrikavälisteks (nt Prince 1980: 531 (kasutades erinevat terminoloogiat); Hayes 1995: 317; Eek, Meister 2004: 338), sest sõnalõpuline lühikese koodakonsonandiga CVC-silp ei tõmba enesele kaasrõhku: sõnas kavalad ei ole viimane silp kaasrõhuline, kuid sõnas kavalat on kaasrõhk viimasel silbil täiesti võimalik. Terminiga meetrikaväline tähistatakse niisuguseid prosoodilisi üksusi, mille suhtes meetrikareeglid on pimedad. Meetrikaväliseid segmente, silpe vm justkui poleks silbistruktuuri ega rõhureeglite jaoks olemas (Hayes 1995: 105-108). Kui sõnalõpu konsonandid on meetrikavälised, siis sõna kavalad lõpusilpi näevad rõhureeglid kerge CV-silbina, mis ei saa moodustada omaette jalga ega olla sõnalõpulisena kaasrõhuline: /('ka.va).la $<\mathrm{t}>$ /. Sõna kavalat lõpus aga väidavad Hayes (1995: 317), Eek ja Meister (2004: 338) olevat kahe $t$ järjendi, mitte pika klusiili. Viimane neist kahest $t$-st on meetrikaväline, esimene aga muudab silbi raskeks ning seega kaasrõhuliseks, vrd /('ka.va).( lat $<\mathrm{t}>$ )/ ja /('ka.va).la $<\mathrm{t}>/$.

Niipea, kui loobume aktiivsest asendikaalu reeglist eesti keeles ning eeldusest, et fortisklusiil on kahe identse hääliku järjend, võib kogu eelnevas lõigus kirjeldatud keeruka struktuurikirjelduse ära unustada. Sõna kavalad lõpusilp on kerge, sest ta on leksikonis ühemooraline ning pole ühtegi aktiivset protsessi, mis lisaks teise moora. Sõna kavalat lõpusilp on aga raske, sest sisaldab leksikaalset mooraga seotud klusiili. Kaasrõhuline saab olla ainult raske silp.

Eesti keele varasematel arenguetappidel on asendikaalu reegel küllap siiski olnud aktiivne (nagu tänapäevases soome keeleski). Rõhulise silbi kooda kunagist mooralisust tõendab asepikendus sõnades, nagu *kansak > kaasa (samamoodi vadja ja liivi keeles): kui konsonant kadus, jäi alles nn vaba moora, mis seondus eelneva vokaaliga, muutes selle pikaks (vt Hayes 1989: 262). Rõhutud silbid olid aga tõenäoliselt ühemooralised. Sellele viitab algläänemeresoome astmevaheldus, mis on hõlpsalt seletatav kerge silbi kahetise struktuuri abil: lahtises silbis oli moora jagatud tuuma ja esiku vahel, kinnises silbis aga tuuma ja kooda vahel (vt täpsemalt Prillop 2011).

Üsna tõenäoliseks võib pidada kahesilbilise jala rõhulise silbi kooda nõrgenemist (st moora kaotamist) seoses ühesilbiliste jalgade tekkega, sest nõnda saab vähendada erineva struktuuriga silpidest moodustuvate jalgade suuri pikkuserinevusi (vrd Eek, Meister 2004: 345). (CV.CV)-jalad on igal juhul kahemooralised, enamik varasemaid kolmemooralisi (CVX.CV)-jalgu oli asendunud samuti kahemooraliste (CVX)-jalgadega (nt *(ham.pa).(hi.ta) > *(ham).(pai.ta), *(sil.mä).tä > *(sil).(mä̈̈) jmt), kuid (CVX.CVC)-jalad olid endiselt kolmemooralised. (CVC.CVC)-jala sai muuta teistega ühtmoodi kahemooraliseks, jättes esisilbi kooda ilma moorata. Niisiis, II-välteliste sõnade esisilbi nõrgenemise põhjuseks võib olla püüdlus jalaisokroonia (jalgade samakestuslikkuse) poole. Jalaisokroonia ei tähenda, et kestus rõhulise silbi algusest järgmise rõhulise silbi alguseni peab olema alati umbkaudu sama. Eesti keeles võib rõhusilpide vahel olla null kuni kaks rõhutut silpi. Jalaisokrooniat tuleks siin mõista kui keele püüdlust kasutada eranditult mooratrohheilisi, st 
sõnad kinnise esisilbiga ja seega II vältes. Samas on nad kerge esisilbiga ning seega siiski pigem I vältes. Oletan, et nimelt niisugused sõnad on kaasa toonud (või toomas) kerge kinnise esisilbiga sõnade laiema leviku, st lõpliku loobumise asendikaalu reeglist.

Kui täielik on asendikaalu reegli hülgamine tänapäeva eesti keeles, võiks olla võimalik otsustada mõõdetud häälikukestuste põhjal. Kuigi mooral ei ole kindla kestusega foneetilist korrelaati, saab võrrelda sarnase häälikkoostisega sõnu. Kui üksikkonsonandiga lõppev silp ei ole II vältes kahemooraline, siis peaks sama häälikkoostisega silbi kooda III vältes pikenema lisamoora ning jala lõpupikenduse võrra; fortisega lõppev silp pikeneks aga ainult lõpupikenduse võrra, sest on kahemooraline ka II vältes. Hüpoteesi testimiseks sobivaid mõõtmisi, kuigi hoopis muul eesmärgil, on teinud Eek ja Meister (2004: 267-270); vt tabelit 2. Kahjuks on Eegi ja Meistri andmestikus esitatud ainult keskmised väärtused, aga mitte hajuvuskarakteristikud (vt originaalandmestikku Eek, Meister 2004: 267, 269 tabelitest 1 ja 2).

Tabel 2.

\section{Koodakonsonantide kestused II ja III vältes (Eek, Meister 2004 põhjal)}

\begin{tabular}{|c|c|c|c|c|}
\hline \multirow[t]{2}{*}{ Osa } & \multirow[t]{2}{*}{ Sõna } & \multicolumn{2}{|c|}{ Esisilbi kooda kestus (ms) } & \multirow{2}{*}{$\begin{array}{l}\text { III ja II välte esisilbi } \\
\text { kooda kestuste suhe }\end{array}$} \\
\hline & & II vältes & III vältes & \\
\hline \multirow[t]{2}{*}{ a. } & /põtra, põt: ra/ & 50 & 161 & 3,22 \\
\hline & /ritva, rit:-va/ & 65 & 158 & 2,43 \\
\hline \multirow[t]{2}{*}{ b. } & /rüt:mi, rüt:'mi/ & 118 & 185 & 1,57 \\
\hline & /rit:va, rit: $: \mathrm{va} /$ & 124 & 158 & 1,27 \\
\hline \multirow[t]{7}{*}{ c. } & /käsna, käs:'na/ & 68 & 194 & 2,85 \\
\hline & /vihma, vih: ma/ & 66 & 170 & 2,58 \\
\hline & /kalmu, kal:'mu/ & 55 & 120 & 2,18 \\
\hline & /kasta, kas:- ta/ & 69 & 128 & 1,86 \\
\hline & /varsa, var: si/ & 78 & 154 & 1,85 \\
\hline & /pakti, pak: ti/ & 77 & 124 & 1,61 \\
\hline & /karta, kar: $\cdot$ ta/ & 81 & 116 & 1,43 \\
\hline
\end{tabular}

Tabeli $a$-osast nähtub, et nii moora kui ka lõpupikenduse lisandumisel suureneb koodakonsonandi kestus enam kui kaks korda. $b$-osast on näha, et lõpupikendus üksi suurendab kestust umbes 1,5 korda või vähem. Tabeli $c$-osas on sõnad, mille esisilbi kooda võib II vältes teoreetiliselt olla nii mooraga seotud kui ka sidumata. Kolm esimest neist sõnadest toetavad kerge esisilbi hüpoteesi; kasta ja varsa on midagi vahepealset, pakti ja karda aga pigem raske esisilbiga. Absoluutkestuste järgi (kõik sõnad olid loetud võrreldava tempoga) on $c$-osa sõnad sarnasemad $a$-osa sõnadega, st pigem kerge esisilbiga. Võib ka oletada, et kuna sonoorse kooda võimalik mooralisus ei mõjuta kuidagi sõna tähendust, siis see ikkagi varieerub, olgu siis inimeseti, häälikuti, vastavalt lausefookusele või mõnel muul põhjusel. 


\section{Vanad ja uued tüvevaheldused morfoloogias}

Lihtsast silpide fonoloogilisest kirjeldusest on huvitav edasi minna morfoloogiasse ning selgitada, kuidas ja miks moodustuvad astmevahelduslike sõnade erinevas vältes tüviallomorfid. EKG (1995: 150-151) eristab välte- ja pikkusmuutust: vältevahelduse korral muutub ainult välde (nt erinevad vormid sõnast silm), pikkusvahelduse korral aga kaasneb vältemuutusega pika klusiili või $s$-i asendumine lühikese klusiili või $s$-iga (nt paat : paadi, poiss : poisi).

Kui peame sõna pelgalt lineaarseks häälikujadaks, tuleb defineerida kolm erinevat konteksti, kus pikkusmuutus toimub. Pikkusmuutus leiab aset sõnades, milles fortis järgneb 1) pikale vokaalainesele, nt paat : paadi, koit : koidu, või 2) sonoorsele (helilisele) konsonandile, nt kont : kondi, või 3) lühikesele vokaalile ja eelneb sonoorsele konsonandile, nt latv : ladva. Häälikuühend $t m$ siiski ei allu kunagi pikkusmuutusele, nt rütm, logaritm, algoritm (EKG 1995: 153-154). Viimaste puhul on tegemist suhteliselt noorte laenudega. Ülejäänud sõnad, kus fortisklusiil eelneb sonoorsele konsonandile (latv, ritv ja lõtv), on aga läänemeresoome tüved ning struktuurilt sarnased põder-mäger-tüüpi sõnadega, mis samuti kuuluvad paar tuhat aastat vanasse sõnavarakihistusse (balti või alggermaani laenud). Lühikese vokaali järel ega helitu konsonandi ees pikkusmuutust ei toimu, nt pott : poti, laps : lapse.

Keeleajalooliselt on kahes esimeses nimetatud sõnagrupis, kus fortis järgneb pikale vokaalainesele või sonoorsele konsonandile, tegemist algläänemeresoome tüvelise astmevahelduse edasiarenguga, st nähtusega, mis mõjutas silpide algusklusiile ja mille tõttu kujunes eelkõige laadivaheldus. Vältevaheldus, erinevalt laadivaheldusest, mõjutab silbikooda häälikuid. Sõnad, milles klusiil eelneb sonoorsele konsonandile, ei allunud algläänemeresoome tüvelise astmevahelduse reeglitele, sest neis polnud teise silbi algul klusiili, mis saanuks nõrgeneda. Pikkusmuutus nendes sõnades on kujunenud analoogselt vältevaheldusega muudes sõnatüüpides ning erinevad tüvevariandid moodustatakse just nagu muudestki vältevahelduslikest sõnadest. Pikkusmuutus oleneb sellest, kas klusiil on leksikaalselt mooraga seotud või mitte. Vanemas sõnavaras ei ole silbikooda klusiilid leksikaalselt mooraga seotud (nt $l a t v$, vrd isuri ladva, vepsa ladv), aga uuemates laenudes võivad olla (nt rütm, nitro, makro).

Vormimoodustusel peavad vältevahelduslike sõnade nõrgaastmeline tüvevariant ja tugevaastmeline tüvevariant sobituma kumbki omasse struktuurisängi, mis on kujutatud joonisel 4. Nõrgaastmelises vormis peab jalg koosnema kahest silbist (joonis 4a), kusjuures nende silpide struktuur pole tegelikult oluline; tugevaastmelises vormis peab aga esisilp moodustama omaette jala (joonis $4 b$ ).

a. NA:

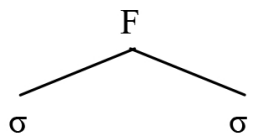

b. TA:

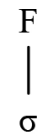

J o o n is 4. Nõrgaastmelise (NA) ja tugevaastmelise (TA) vormi struktuurisängid. 
Kui sõna süvaesituses pole leksikaalset mooraga seotud silbilõpulist klusiili (vt joonist 5), on nõrgaastmelise tüvevariandi moodustamine väga lihtne. Sellisteks sõnadeks on näiteks silm, karv; latv, ritv; põder, mäger.

$\begin{array}{ccccc} & \text { | } & & & \\ \mathrm{s} & \mathrm{i} & \mathrm{l} & \mathrm{m} & \mathrm{a} \\ \mathrm{m} & \text { ä } & \mathrm{k} & \mathrm{r} & \mathrm{a} \\ \mathrm{l} & \mathrm{a} & \mathrm{t} & \mathrm{v} & \mathrm{a}\end{array}$

J o o n is 5. silm-, mäger- ja latv-tüüpi sõnade süvaesitus.

II-vältelise vokaallõpulise tüviallomorfi moodustamiseks on vaja joonisel 5 esitatud leksikaalne struktuur sobitada struktuuriga joonisel 4a. Protsessi illustreerib joonis 6. Esmalt paigutatakse silpidesse moorad, seejärel mooraga sidumata konsonandid, arvestades universaalse põhimõttega, et silbil peab olema alguskonsonant, aga konsonantühendeid silbialguses välditakse. Niisiis, nõrgaastmelistes vormides mägra ja ladva säilib leksikaalne leenisklusiil, sest tänapäevases keeles ei ole ühtegi aktiivset protsessi, mis seoks selle klusiili mooraga.

a.

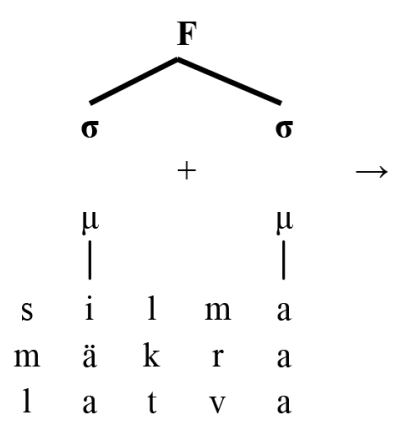

b.

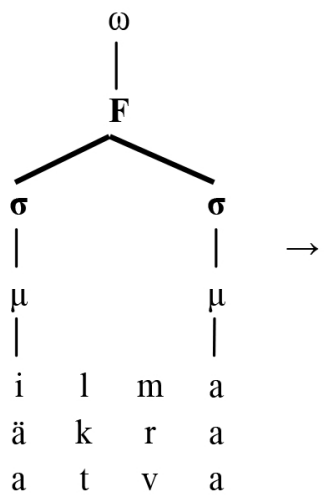

c. $\omega$

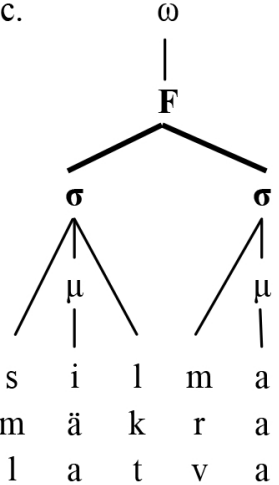

Jo o n is 6. Nõrgaastmelise vokaaltüve moodustumine silm-, mäger- ja latv-tüüpi sõnadest (silma-, mägra-, ladva-).

III-vältelise tüve jaoks on vaja esisilbi lõppu lisada moora, sest tüvevariant peab sobituma struktuurisängi joonisel $4 \mathrm{~b}$, kuid ei tohi rikkuda universaalset tingimust, mis keelab ühemooralised jalad. Tuletusprotsess on esitatud joonisel 7: kui olemasolevad moorad on struktuuri paigutatud, jääb esimest silpi domineeriv jalg ühemooraliseks ja sellesse tuleb lisada mitteleksikaalne moora (joonis $7 \mathrm{~b}$ ). See lisatud moora saab kuuluda vaid silbikoodasse (joonis $7 \mathrm{c}$ ), sest mooraga seotud konsonandid silbi alguses on universaalselt keelatud. 
a.

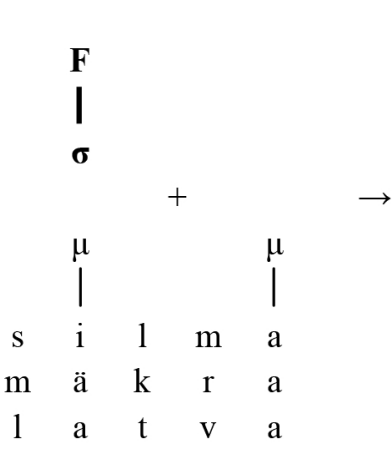

b.

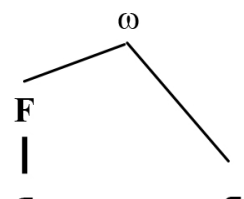

c.

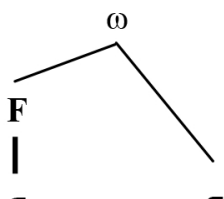

J o o n is 7. Tugevaastmelise vokaaltüve moodustumine silm, mäger ja latv tüüpi sõnadest (silma-, mäkra-, latva-).

Nimetavas käändes esile tuleva konsonanttüve moodustamiseks tuleb teada, millistesse sõnalõpulistesse konsonantühenditesse tekkib epenteetiline $e$. Kui sõnasse ei lisata vokaali, siis lisatakse ikkagi moora, et ei moodustuks ühemooralist jalga, nt /sil:'m/, /lat:'v/. Sonoorsele konsonandile eelnev klusiil sellistes vormides on seega alati fortis. Kui aga sõna muutub epenteetilise vokaali tõttu kahesilbiliseks, siis pole konsonandiga ühendatud lisamoorat vaja, nt /mä.ker/.

Veelgi lihtsam tüvevariantide moodustusprotsess toimub neis vältevahelduslikes sõnades, kus esisilbi lühikesele vokaalile järgnev konsonant on süvatasandil mooraga seotud. Vanemas sõnavaras on see võimalik ainult vokaali ees (nt konna, kappi, mõte), uuemas sõnavaras ka konsonandi ees (nt rütmi, algoritmi). Kuna nõrga astme struktuur (joonis 4a) ei keela kahemooralist esisilpi - II väldet eristab III vältest silpide arv jalas, mitte esisilbi moorade arv -, siis kõik leksikaalsed moorad säilivad ja muutub ainult välde (vt jooniseid 8 ja 9).

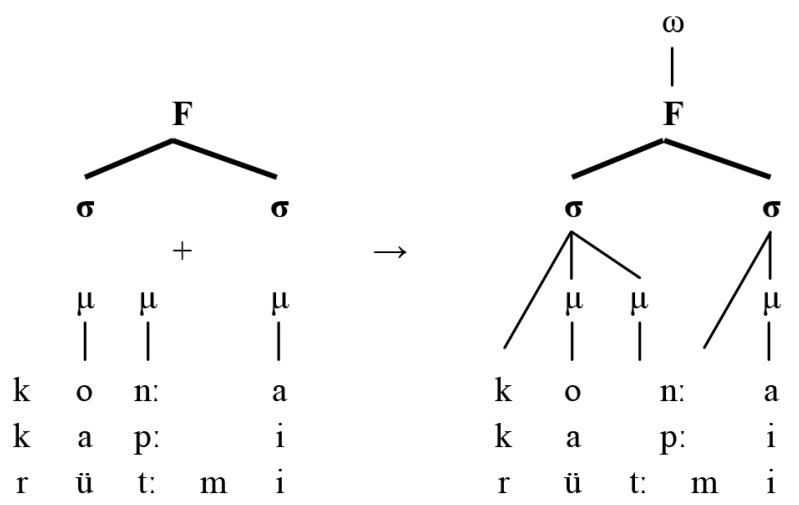

J o o n is 8. Nõrgaastmelise vokaaltüve moodustumine konn-, kapp- ja rütm-tüüpi sõnadest. 


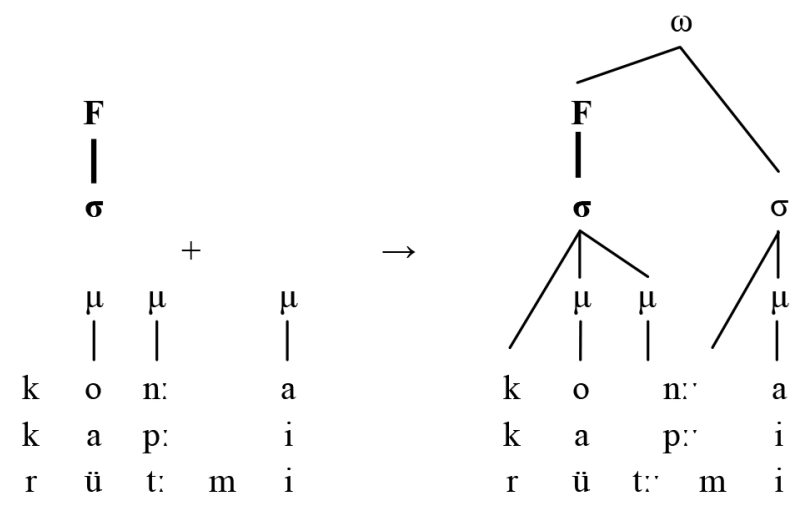

J o o n is 9. Tugevaastmelise vokaaltüve moodustumine konn-, kapp- ja rütm-tüüpi sõnadest.

Leksikaalselt mooraga seotud konsonant peab olema ka nendes sõnades, kus praegune nn pikkusmuutus on kujunenud algläänemeresoome tüvelisest astmevaheldusest, st sõnades, kus pikale vokaalile, diftongile või sonoorsele konsonandile järgneb leksikaalselt mooraga seotud obstruent (nt koot, poiss, palk). Muul moel ei ole võimalik eristada sõnu koot ja kood, laut ja laud jpt. Neis sõnades on vaja kuidagi vältida kolmemooralise silbi moodustumist (kehtib universaalne piirang, et silbis on maksimaalselt kaks moorat).

Tugevaastmelise tüvevariandi korral võib kolmest moorast kaks omavahel ühendada, nii et kaks segmenti jagavad sama moorat (vt joonist 10). Niisamuti tuleb moorat jagada ka konsonandile järgneva geminaadi puhul, sest teisiti ei saa seda konsonanti puusse ühendada (tasandite vahelejätmine on lubatud vaid üksuste piiril), vt joonist 11 . Et moora jagamine sellises positsioonis tõepoolest toimub, kinnitavad ka mõõtmistulemused. Näiteks sõnas saada (III välde) on esisilbi pika vokaali kestuseks keskmiselt $238 \mathrm{~ms}$, aga sõnas saata ainult 165 ms; klusiil sõnas katta vältab 248 ms, aga sõnas saata ainult 178 ms; st pikk vokaal annab osa oma teisest moorast ning seega ka kestusest järgnevale klusiilile (vt mõotmistulemusi Eek, Meister 2003: 905).

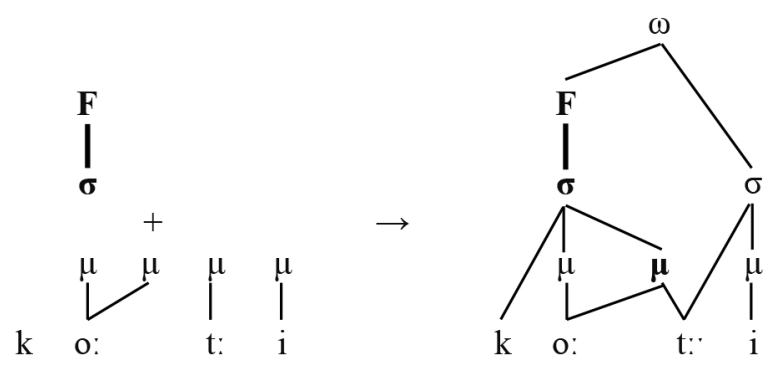

J o o n is 10. Tugevaastmelise vokaaltüve moodustumine sõnast koot. 


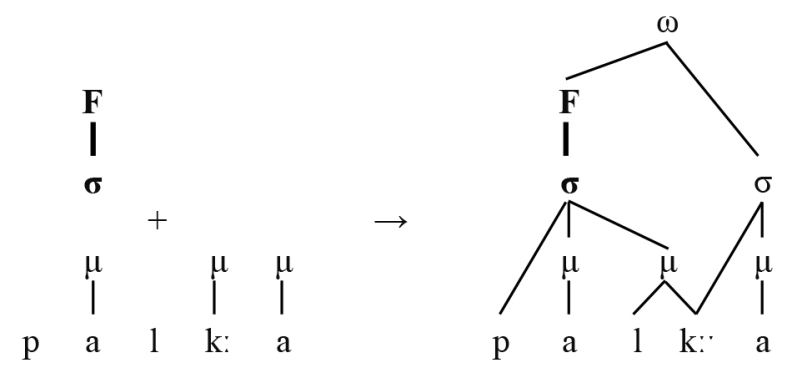

J o o n is 11. Tugevaastmelise vokaaltüve moodustumine sõnast palk.

Samamoodi saaks jagada ka jalasisest, pikenemata moorat II vältes. Mõõtmistulemused niisugust tõlgendust siiski täielikult ei toeta. Lehiste (2003: 52, mõõtmised aastast 1977) järgi on vokaal sõnas gooti küll lühem kui sõnas koodi (II välde) ning klusiil sõnas gooti lühem kui sõnas koti, aga Eegi ja Meistri järgi (2003: 905) on need erinevused üliväikesed: esisilbi vokaali kestus sõnas saada (II välde) on keskmiselt $172 \mathrm{~ms}$ ning sõnas saate $154 \mathrm{~ms}$ (standardhälve mõlemal juhul üle $30 \mathrm{~ms}$ ); klusiil sõnas kata $144 \mathrm{~ms}$ ning sõnas saate $140 \mathrm{~ms}$ (standardhälbed alla $15 \mathrm{~ms}$ ). Võimalik, et jalasisese moora jagamine ei ole eesti keeles tegelikult üldlevinud ning tabel 1 kajastab vaid korrapärast, idealiseeritud keelevarianti, üht mitmetest võimalustest, milleni eesti keel võinuks areneda. Jätkan seda arutelu peatükis 3 .

a.

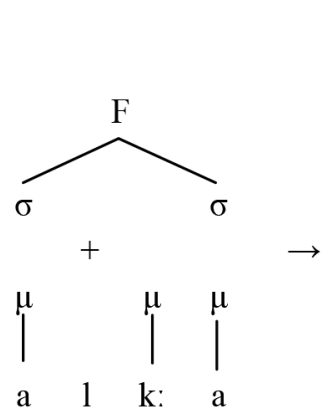

c.
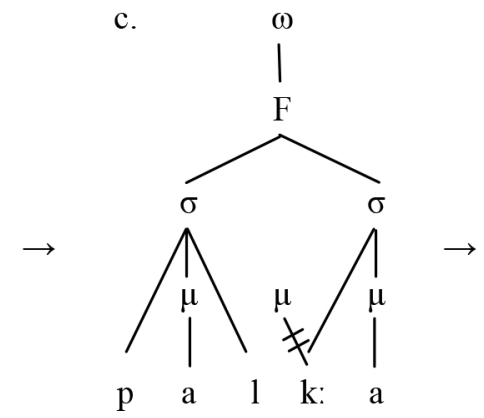

b.

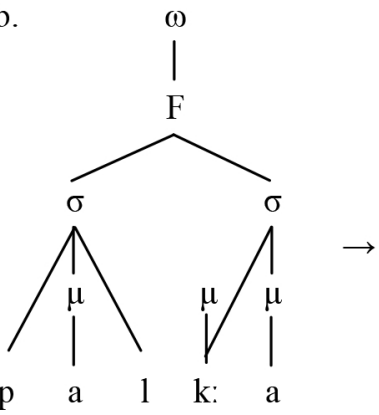

d.

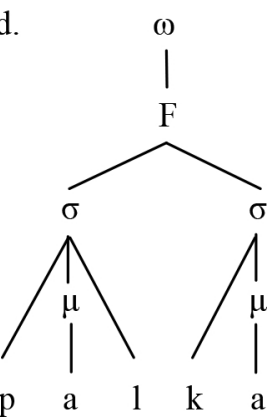

J o o n is 12. Degemineerumine II vältes. 
Jalasisese moora jagamine ei olnud võimalik eesti keele varasemal arenguetapil - ajal, mil kujunesid degemineerunud klusiiliga nõrgaastmelised vormid sõnades koot : koodi, palk : palgi, poiss : poisi jt. Kolmemooraliste silpide vältimiseks neis sõnades tuli leksikaalne moora kaotada, mis põhjustaski degemineerumise nõrgas astmes; vt tuletusprotsessi joonisel 12. Leksikaalselt mooraga seotud klusiili ei saa paigutada teise silpi, sest iseseisva mooraga seotud konsonant silbi alguses pole lubatud. Samuti ei mahu selline klusiil esisilpi, sest seal on juba mooraga sidumata koodakonsonant, millele ei saa enam järgneda mooraga seotud koodakonsonant (üksusesisene tasandite vahelejätmine pole lubatud). Vastuvõetava struktuuri saab moodustada juhul, kui klusiili moora eemaldada.

\section{Kvantiteedikeelest tooniaktsendikeeleks}

Tänapäeva eesti keeles on geminaatklusiil võimalik ka positsioonides, kus see varasemalt oleks asendunud üksikklusiiliga: II vältes esisilbi pika vokaalainese või vokaali ja sonoorse konsonandi järel. Sellised on mitmed uuemad astmevahelduseta laensõnad (nt auto, konku, polka, ärtu), üksikud kõikuva vältega sõnad, mis on muuttüüpi vahetamas (nt päike, väike, äike); te-mitmuse analoogiavormid (nt suurte, koerte) ja mitmuse 2. pöörde vormid (nt näete, naite). Nende sõnade struktuuri esitamiseks ei ole siiski ilmtingimata vaja klusiili moorat eelneva häälikuga jagada. Võimalik, et tegemist on hoopiski lühikese geminaadiga (vt joonist 13). Moorateoorias on geminaat defineeritud kui mooraga seotud konsonant, seega peaks geminaadiga lõppev silp olema igal juhul raske. Pindstruktuuris see pole siiski alati nii. Näiteks samojeedi keelte hulka kuuluvas sölkupi keeles ja draviidi keelkonna malajalami keeles on geminaadiga lõppevad silbid kerged (vt Tranel 1991). See pole teooriaga vastuolus, sest geminaat võib oma leksikaalse moora pindstruktuuris kaotada, jäädes siiski kahe silbi vahel jagunenud konsonandiks.

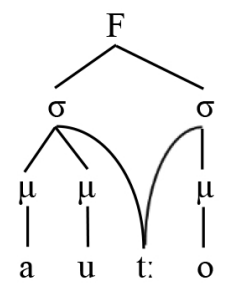

J o on is 13. Lühike geminaat.

Eesti keele lühikesed geminaadid hakkasid kõige tõenäolisemalt levima vormidest, nagu varte ja uute, kus algselt on tegu identsete klusiilide järjendiga tüve ja tunnuse piiril, mitte geminaadiga (identsete klusiilide järjend kujunes

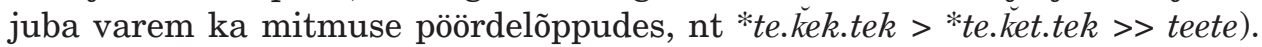
Tänapäeva eesti keele mitmuse tunnus -de- on kujunenud läänemeresoome algkeele läänepoolsetes murretes $t$-lõpulisest mitmuse nominatiivist, millele 
liideti sidevokaali vahendusel genitiivi lõpp -n (Rätsep 1982: 37). Klusiil selles tunnuses ei olnud mooraga seotud. Kuna kahetüveliste sõnade mitmuse omastav kujunes osastava eeskujul konsonanttüveliseks, tekkis osas sõnades kahe $t$ järjend, nt *uut+ten, *vart+ten, *kastek+ten > (assimilatsioon) *kastet+ten. Kahesilbilistes sõnavormides kinnise silbi ees kaotasid algupärased geminaatklusiilid oma moora ning muutusid üksikklusiilideks (laut : lauda : lauta), kuid kahe $t$ järjend tüve ja tunnuse piiril astmevahelduse reeglitele ei allunud (vt joonist 14).

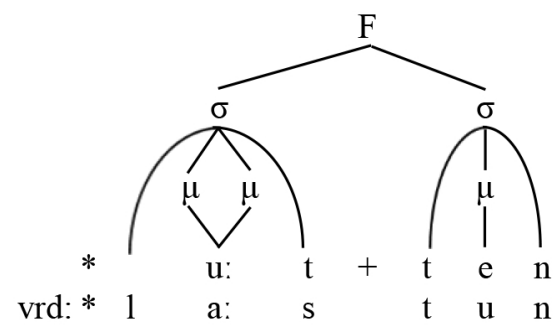

J o o n is 14. Identsete klusiilide järjend tüve ja tunnuse piiril võrdluses tüvesisese konsonantühendiga.

Tüve ja tunnuse piirile jääv $t t$ reanalüüsiti tervikuna tunnusesse kuuluvaks ning seega paratamatult ka leksikaalselt mooraga seotuks hiljemalt siis, kui kadusid nõrgenenud klusiilid ning polnud enam põhjust pidada $t$-d tüvesse kuuluvaks (vrd *kastek: *kasteke+n: *kastet+ten > kaste : kaste : kaste+te; *uusi: *uute+n: *uut+ten > uus : uue : uu+te). Identsete häälikute järjendeid välditakse, kuna need läheks vastuollu universaalse printsiibiga, mis keelab kõrvutised identsed elemendid ühe morfeemi piires (ingl obligatory contour principle; vt McCarthy 1986; Keer 1999: 22-50).

Reanalüüs võimaldas t:e-tunnusel levida uutesse sõnatüüpidesse (nt häälikuseadusliku madala asemel madalate, keele asemel keelte), aga sellega pidi kaasnema kas lühikeste geminaatide teke või tüvesisese moora jagamine. Moora jagamine muudab pindstruktuuri häälikute kestusi: klusiil pikeneb (sest on nüüd mooraga seotud, vrd jooniseid 15a ja 15b) ning sellele eelnev pikk vokaal lüheneb samavõrra (sest jagab oma teist moorat järgneva klusiiliga). Lühikese geminaadi puhul jäävad häälikute kestused endiseks, mistõttu see võis olla soositum variant (vrd jooniseid 15a ja 15c).

a.

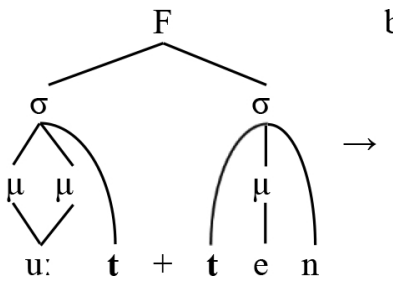

b.

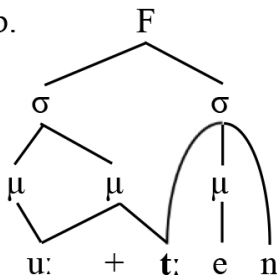

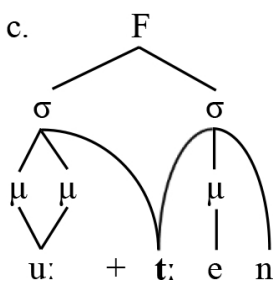

J o on is 15. Mitmuse osastava tunnuse reanalüüs. 
Tänapäevases eesti kirjakeeles on hulk niisuguseid konsonanttüvelisi mitmuse genitiivi vorme, mille struktuuri ei ole võimalik esitada jagatud moora abil, kuid on võimalik, kui lubada lühikesi geminaate: kaarte, noorte, suurte jt keel-tüüpi sõnade analoogiavormid (keeleajalooliselt ootuspärane oleks tüvelise astmevahelduse tõttu *kaarten $>$ *kaare). Võiks eeldada, et nende sõnade tänapäevane mitmuse osastava struktuur on samasugune kui lühema esisilbiga sõnadel varte ja uute, st et kõigis neis vormides on lühike geminaat. Enne seda, kui oli kujunenud tie-tunnus, polnud lühikesed geminaadid võimalikud ning klusiili moora kadu tähendas degemineerumist (nagu sõnades koot : koodi või palk : palgi). Lühikese geminaadi tuletusprotsess erineb degemineerumisest selle poolest, et moora kaotatakse alles pärast seda, kui selle mooraga seotud häälik on silpi lisatud (vt joonist 16).

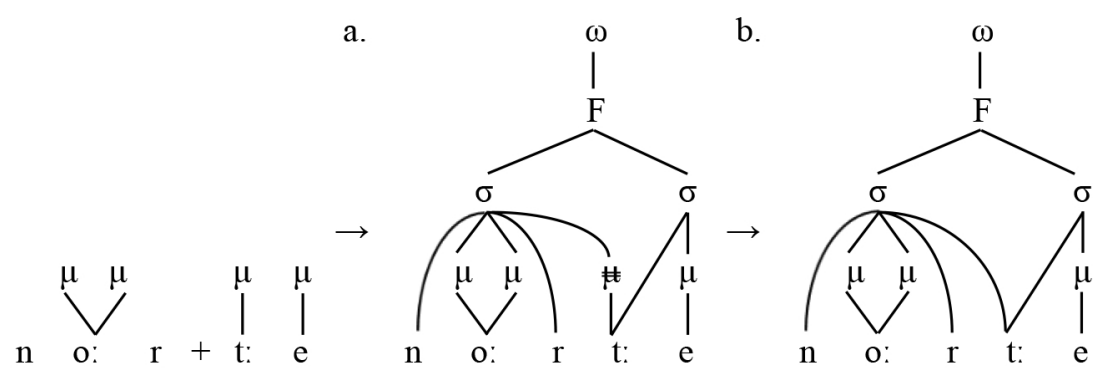

J o o n is 16. Lühikese geminaadi kujunemine II vältes.

Võimalik, et eesti keeles on lühikesed geminaadid levimas (või juba levinud) ka sõnadesse, milles leksikaalsele geminaatklusiilile eelneb lühike vokaal, nt $k a p i$ või ute. Seda võiks tõlgendada kui olulist uuendust teel silptrohheilisest keelest mooratrohheiliseks. Kui seni olid keeles nii mooralised trohheused (kahemooralised jalad) kui ka silbilised trohheused (kahesilbilised jalad), siis nüüd jääks silptrohheiliseks ainult väike osa II-vältelisi (CVX.CV)-jalgu. Seejuures muutub vaid sõnade sisemine struktuur, mitte pindvormi häälikud.

Oletust, et II-vältelistes sõnades on üldisemalt hakatud vältima rasket esisilpi, toetavad ka Eegi ja Meistri mõõtmistulemused, mis on esitatud juba peatükkides 1 ja 2 . Näiteks sõnades katta ja kata on III ja II välte esisilbi kooda kestuste suhe 2,3 (vt Eek, Meister 2003: 905). Lõpupikendus üksi suurendaks kestust kuni 1,5 korda, st vormis katta näib olevat võrreldes vormiga kata terve lisamoora, mitte pole tegemist ainult moora pikenemisega.

Kõikide II-välteliste sõnade esisilpe ühemooraliseks muuta ei saa. Sõna esisilpi jääb kaks moorat, kui selles silbis on pikk vokaal, diftong või sonoorsele konsonandile eelnev fortisklusiil. Nii et esisilpe nõrgendades ei saa eesti keel areneda päris mooratrohheiliseks, ilma et kaoks kolmikvastandused nagu /koli - ko:li - ko:-li/ (esisilbi nõrgendamise tulemus oleks/koli - koli - ko :-li/). Teoreetiliselt on võimalik, et pika esisilbiga sõnades hakkab kunagi väldet eristama ainult toon, mitte erineva ehitusega jalad pindstruktuuris. Sel juhul saaks eesti keel täielikult loobuda kolmemooralistest jalgadest ning minna üle mooratrohheilisele rõhusüsteemile. 
Põhitooni muutumise eesti keeles määrab jala struktuur. Olenemata silpide arvust jalas, jala alguses põhitoon ei muutu või tõuseb, jala lõpus aga langeb. Seega, III välte sõnades hakkab põhitoon langema juba esisilbi keskel, teise silbi toon on madal. II ja I vältes aga algab langus esisilbi lõpus ning kestab teise silbi lõpuni (Lippus 2016: 141; Asu 2016: 169).

Koos toonierinevustega on eesti keeles viis kontrasti, mis omavahel kombineeruvad ja millest oleneb sõna välde pindstruktuuris:

1. lühike vs. pikk vokaal,

2. mooraga sidumata vs. mooraga seotud üksikkonsonant,

3. mooraga sidumata vs. mooraga seotud geminaatkonsonant,

4. ühe- $v s$. kahesilbiline jalg,

5. sõnade erinevad toonikontuurid.

Kõiki nimetatud eristusi ei ole vaja, et säilitada leksikaalseid kontraste. Esiteks, geminaatkonsonandi mooralisus tuleneb sellest, kas jalg on ühe- või kahesilbiline: kahesilbilises jalas geminaadi moora kaob, et jalg sobiks mooratrohheilisesse süsteemi. Teiseks, ka põhitooni kontuur oleneb sellest, kas jalg on ühe- või kahemooraline, kuid pärast silpidele tooni omistamist võib ebasobivad pikast ja lühikesest silbist koosnevad jalad pindstruktuuris asendada ühesilbilistega, sest toonieristus on sõnatähenduste lahus hoidmiseks piisav. Kui kunagi kaugemas tulevikus muutuks ka teise silbi toon tähendusi eristavaks, siis saaks loobuda lühikestest geminaatidest ning kogu süsteem oleks väga sarnane näiteks rootsi keelele. Hüpoteetiline mooratrohheilise keele „vältesüsteem”, kus on lubatud ainult kahemooralised jalad ning pindstruktuuris kasutatakse väldete eristamiseks seetõttu põhitooni, on esitatud tabelis 3 . Nooleke > tähistab struktuurimuutust võrreldes tabelis 1 esitatuga. Tsirkumfleks märgib langevat, graavis madalat ja akuut ühtlast kõrget või veidi tõusvat tooni. Tähenduste eristamisel on oluline eelkõige tsirkumfleks, teised toonid on üheselt määratud tsirkumfleksi asukohaga. Võimalik, et II vältes sõnade esisilp, mis uues süsteemis moodustab ühesilbilise jala, häälduks ikkagi tervele jalale iseloomuliku toonikontuuriga nagu III vältes sõna esisilpki, aga erinevus väldete vahel ilmneks just teises silbis: II vältes oleks seal uus tõus ning langus, III vältes oleks toon madal. On tähelepanuväärne, et teistegi Läänemere areaali keelte tooniaktsente saab kirjeldada prosoodilisest struktuurist tulenevaina (nt Morén-Duolljá 2013; Köhnlein 2016).

\section{Eesti vältesüsteemi teisenemine (hüpoteetiline)}

Tabel 3.

\begin{tabular}{|c|c|c|c|}
\hline Välde & I & II & III \\
\hline Esisilp & kerge & \multicolumn{2}{|c|}{ raske } \\
\hline Jalg & $(\sigma \sigma)$ & \multicolumn{2}{|c|}{$(\sigma)_{\sigma}$} \\
\hline Näited & (ú.tê) $-u d e$ & $\begin{array}{l}>(\text { ú: }) \cdot \text { tê }- \text { uude } \\
>\text { (út.tê) }>\text { (út:).tê }-u t e \\
>\text { (ú:t).tê - uute }\end{array}$ & $\begin{array}{l}(\hat{\mathbf{u}}:) \cdot \mathrm{tè}-u u d e \\
(\hat{\mathbf{u}} \mathrm{t}:) \cdot \mathrm{tè}-\text { utte } \\
(\hat{\mathbf{u}}: \mathrm{t}:) \cdot \mathrm{tè}-\text { uute }\end{array}$ \\
\hline
\end{tabular}

Eesti keele väldete süsteem, mis on maailma keelte hulgas haruldus, ei ole stabiilne. Täpsemate arengute väljaselgitamiseks oleks vaja ulatuslikumaid foneetilisi mõõtmisi, mis hõlmaksid erineva struktuuri ning häälikkoostisega 
sõnu. Näiteks, kas sonoorse geminaatkonsonandiga sõnad on sarnasemad geminaatklusiiliga sõnadele või pika vokaaliga sõnadele; kas jalalõpu pikendus on kadumas; kas on mingeid märke rõhutu silbi tooni olulisusest geminaatklusiiliga sõnades?

\section{Kokkuvõte}

Enne seda, kui eesti keelest saab tooniaktsendikeel, peaks muutuma rõhusüsteem: praegustele II välte sõnadele iseloomulikud jalad, kus esimene silp on raske ning teine kerge, peaks kõigepealt asenduma mooratrohheiliste jalgadega. Mooratrohheilises süsteemis võib jalas olla maksimaalselt kaks moorat, st võimalikud on kahest kergest silbist koosnevad jalad (nagu praegu I vältes) või ühest raskest silbist koosnevad jalad (nagu praegu III vältes), mitte aga raskest ning kergest silbist ega kahest raskest silbist koosnevad jalad.

Suundumusi mooratrohheilise süsteemi poole on märgata juba praegu. Mõõtmistulemused osutavad, et II vältes ongi võimalik kinnine ühemooraline esisilp, seda isegi geminaatkonsonandiga sõnades. Esimesed kinnised kerged silbid tulid keelde arvatavasti siis, kui seoses lõpukaoga tekkis silbilõpu leeniste ning fortiste eristus. Pindstruktuuris ilma moorata geminaadid ilmusid aga seoses konsonanttüvele liituva mitmuse tunnuse -t.e- väljakujunemisega. Kui lühikesed geminaadid oleksid olnud keeles võimalikud varem, ei oleks meil praegu morfoloogilist geminaatklusiili vaheldust üksikklusiiliga (koot : koodi, palk : palgi jt).

Kõige keerulisem on mooratrohheilisesse süsteemi sobitada II-vältelisi pika vokaaliga sõnu, sest neist ei saa ühte vokaaliga seotud mooradest lihtsalt ära kaotada, ilma et see tooks kaasa vokaali lühenemise ning seega ka leksikaalsete kontrastide kaotsimineku. Nüüd tulebki mängu jalale iseloomulik põhitoonikontuur, mis III vältes on surutud kokku ühte silpi, I ja II vältes aga ulatub üle kahe silbi. II-välteline sõna võiks olla samasuguse prosoodilise struktuuriga nagu III-välteline sõna, kui toonikontuur jääks endiseks. Sel juhul eristaks II ja III väldet ainult põhitooni languse asukoht sõnas, kvantiteedikontrasti enam poleks.

Kogu siin esitatud hüpoteetiline arengutee moodustab tervikliku süsteemi, kus üks väike muudatus viib loogiliselt järgmiseni. Moorateooria aitab neid teisenemisi selgelt esile tuua. Kuigi struktuurimuutused on „nähtamatud” need ei mõjuta otseselt häälikute kvaliteeti -, on need samamoodi rekonstrueeritavad nagu häälikumuutusedki.

Uurimistööd on toetanud ETAG-i institutsionaalne uurimistoetus „Soome-ugri keelte prosoodiline struktuur ja keelekontaktid" (IUT2-37) ja HTM-i riiklik programm „Eesti keele ajaloo tervikkäsitlus II” (EKKM17-459). 


\section{Kirjandus}

Alber, Birgit 1997. Quantity sensitivity as the result of constraint interaction. Phonology in Progress: Progress in Phonology. Toim Geert Booij, Jeroen van de Weijer. The Hague: Holland Academic Graphics, lk 1-45.

Aris te, Paul 1947. Foneetilisi probleeme eesti keele alalt. Tartu: RK „Teaduslik Kirjandus".

As u, Eva Liina 2016. Eesti keele intonatsioon. - E. L. Asu, Pärtel Lippus, Karl Pajusalu, Pire Teras, Eesti keele hääldus. (Eesti keele varamu II.) Tartu: Tartu Ülikooli Kirjastus, lk 161-188.

Davis, Stuart 2014. Quantity. - The Handbook of Phonological Theory. (Blackwell Handbooks in Linguistics.) Toim John A. Goldsmith, Jason Riggle, Alan C. L. Yu. Wiley-Blackwell, lk 103-140.

E ek, Arvo, Mei s ter, Einar 2003. Foneetilisi katseid ja arutlusi kvantiteedi alalt. Häälikukestusi muutvad kontekstid ja välde. - Keel ja Kirjandus, nr 11, lk 815837; nr 12, lk 904-918.

E ek, Arvo, Mei s ter, Einar 2004. Foneetilisi katseid ja arutlusi kvantiteedi alalt. Takt, silp ja välde. - Keel ja Kirjandus, nr 4, lk 251-271; nr 5, lk 336-357.

Eh a la, Martin 1999. Eesti väldete probleemi üks lahendusi. - Keel ja Kirjandus, nr 6, lk 378-386; nr 7, lk 453-466.

EKG 1995 = Mati Erelt, Reet Kasik, Helle Metslang, Henno Rajandi, Kristiina Ross, Henn Saari, Kaja Tael, Silvi Vare, Eesti keele grammatika I. Morfoloogia. Sõnamoodustus. Trükki toimetanud M. Erelt (peatoimetajana), T. Erelt, H. Saari, Ü. Viks. Tallinn: Eesti Keele Instituut.

Elen ba as, Nine, Kager, René 1999. Ternary rhythm and the lapse constraint. - Phonology, kd 16, nr 3, lk 273-329.

Ha ye s, Bruce 1989. Compensatory lengthening on moraic phonology. - Linguistic Inquiry, kd 20, nr 2, lk 253-306.

H a y e s, Bruce 1995. Metrical Stress Theory: Principles and Case Studies. ChicagoLondon: The University of Chicago Press.

Hint, Mati 1973. Eesti keele sõnafonoloogia I. Tallinn: Eesti NSV Teaduste Akadeemia Keele ja Kirjanduse Instituut.

Hint, Mati 1997. Eesti keele astmevahelduse ja prosoodiasüsteemi tüpoloogilised probleemid. Tallinn-Helsinki: Eesti Keele Sihtasutus.

Hock, Hans-Henrich 1986. Compensatory lengthening: in defense of the concept „mora”. - Folia Linguistica, kd 20, nr 3-4, lk 431-460.

Hy m a n, Larry M. 1985. A Theory of Phonological Weight. Dordrecht: Foris.

Kag er, René 1999. Optimality Theory. Cambridge: Cambridge University Press.

Ka ger, René 2007. Feet and metrical stress. - The Cambridge Handbook of Phonology. Toim Paul de Lacy. Cambridge: Cambridge University Press, lk 195-227.

Karlsson, Fred 2002. Üldkeeleteadus. Tõlkinud ja kohandanud Renate Pajusalu, Jüri Valge, Ilona Tragel. Tallinn: Eesti Keele Sihtasutus.

Ke er, Edward W. 1999. Geminates, The OCP and The Nature of CON. PhD dissertation. The State University of New Jersey.

Köhnlein, Björn 2016. Contrastive foot structure in Franconian tone-accent dialects. - Phonology, kd 33, nr 1, lk 87-123. 
Lehiste, Ilse 2003. Prosodic change in progress: From quantity language to accent language. - Development in Prosodic Systems. Toim Paula Fikkert, Haike Jakobs. Berlin-New York: Mouton de Gruyter, lk 47-65.

Li p p u s, Pärtel 2016. Eesti keele sõnaprosoodia. - Eva Liina Asu, P. Lippus, Karl Pajusalu, Pire Teras, Eesti keele hääldus. (Eesti keele varamu II.) Tartu: Tartu Ülikooli Kirjastus, lk 119-160.

Mc Carthy, John J. 1986. OCP effects: Gemination and antigemination. - Linguistic Inquiry, kd 17, nr 2, lk 207-263.

M c C arthy, John, Prin ce, Alan 1986. Prosodic Morphology. (Käsikiri.) Amherst, MA: University of Massachusetts.

Morén, Bruce 2003. Weight typology: an Optimality Theoretic approach. - The Linguistic Review, kd 20, nr 2-4, lk 281-304.

Morén-Duolljá, Bruce 2013. The prosody of Swedish underived nouns: No lexical tones required - Nordlyd, kd 40, nr 1, lk 196-248.

Prill o p, Külli 2011. Finnic stop gradation as an effect of mora sharing. - Linguistica Uralica, kd 47, nr 3, lk 161-181.

Prillop, Külli 2013. Feet, syllables, moras and the Estonian quantity system. Linguistica Uralica, $\mathrm{nr} 49, \mathrm{nr}$ 1, lk 1-29.

Prillop, Külli 2015. Hääliku-, silbi- ning jalavälde: ühe nähtuse mitu tahku. Eesti ja Soome-ugri Keeleteaduse Ajakiri, kd 6, nr 3, lk 169-195.

Prillop, Külli 2018. Mida teeb moora eesti keeles? - Keel ja Kirjandus, nr 5, lk 345-364.

Prince, Alan 1980. A metrical theory of Estonian quantity. - Linguistic Inquiry, kd 11, nr 3, lk 511-562.

Rät s e p, Huno 1982. Eesti keele ajalooline morfoloogia. I. Õpivahend eesti filoloogia osakonna üliõpilastele. Tartu: Tartu Riiklik Ülikool.

Ta uli, Valter 1954. The origin of the quantitative system in Estonian. - Journal de la Société Fenno-Ougrienne, kd 57. Helsinki, lk 1-19.

Tran el, Bernard 1991. CVC light syllables, geminates and moraic theory. - Phonology, kd 8, nr 2, lk 291-302.

Külli Prillop (snd 1974), PhD, Tartu Ülikooli eesti ja üldkeeleteaduse instituut, eesti fonoloogia teadur, kulli.prillop@ut.ee

\section{Hidden changes in the prosodic structure of Estonian}

Keywords: moraic theory, consonant gradation, Estonian quantity, history of Estonian, tone accent, weight by position

The article discusses the phonological development of the Estonian language. Ilse Lehiste has claimed that Estonian is changing from a quantity language to an accent language. This undergoing change has never been explained theoretically. Based on Moraic Theory, several steps of the change can be distinguished. First, Estonian has deactivated a process that adds moras to syllable codas. As a result, even main-stressed CVC syllables may be monomoraic. According to phonetical measurements, this may be the situation right now, yet the data is somewhat ambiguous as the measurements have been conducted for different reasons, not 
for investigating coda moraicity. If every CVC syllable is monomoraic, then the difference between the first and second quantity lies in the syllable structure (CV vs. CVC); the second and third quantity can be distinguished by syllable weight (light CVC vs. heavy CVC). Before the change, Estonian was a language with syllabic trochees; only in the case of the third quantity a stressed syllable had to fill the whole foot. After the change, Estonian has moraic trochees, except the second quantity words that begin with a CVV syllable. CVV syllables are always bimoraic. Therefore, second and third quantity words are still footed differently to maintain their difference: (CVV.CV) vs. (CVV).CV. The second quantity footing (CVV.CV) does not fit the system of moraic trochees and has to be altered. This can be done by reanalysing the pitch contour, which is characteristic of a foot, as phonological tone.

Külli Prillop (b. 1974), PhD, University of Tartu, Institute of Estonian and General Linguistics, Research Fellow in Estonian Phonology, kulli.prillop@ut.ee 